\title{
Financing Mechanism for Social Long-Term Care Insurance: A Theoretical Analysis Framework
}

\author{
Sun Jie ${ }^{1}$, Hu Xinyi ${ }^{2,}$, , Jiang Yuezhu ${ }^{3}$ \\ ${ }^{1}$ Social Security, School of Insurance and Economics, University of International Business and Economics, Beijing, China \\ ${ }^{2}$ Science of Finance, School of Insurance and Economics, University of International Business and Economics, Beijing, China \\ ${ }^{3}$ Labor Economics, School of Insurance and Economics, University of International Business and Economics, Beijing, China
}

Email address:

Sunjie@uibe.edu.cn (Sun Jie), 710447743@qq.com (Hu Xinyi)

${ }^{*}$ Corresponding author

\section{To cite this article:}

Sun Jie, Hu Xinyi, Jiang Yuezhu. Financing Mechanism for Social Long-Term Care Insurance: A Theoretical Analysis Framework. International Journal of Economics, Finance and Management Sciences. Vol. 8, No. 1, 2020, pp. 39-48. doi: 10.11648/j.ijefm.20200801.15

Received: January 13, 2020; Accepted: January 31, 2020; Published: February 13, 2020

\begin{abstract}
The financing mechanism is an important component of social long-term care insurance, its stability and sustainability have a vital significance in keeping the healthy and efficient operation of social long-term care insurance. In order to carry out an in-depth study on the financing mechanism of social long-term care insurance, this article makes an analysis of each of the links and key points involved in the financing in accordance with the whole process of the social long-term care insurance financing and on the basis of summarizing the existing literature regarding the definition and connotation of the financing mechanism of social long-term care insurance. On such basis, it establishes the financing mechanism element framework of social long-term care insurance, by which it then explores the practices and experiences of the typical countries with social long-term care insurance and the advanced areas of China. Finally, in view of the common points and reform tendency of the construction of foreign countries' social long-term care insurance financing mechanism, this paper puts forward some policy suggestions for the construction of China's social long-term care insurance financing mechanism.
\end{abstract}

Keywords: Social Long-term Care Insurance, Financing Mechanism, Financing Elements

\section{Introduction}

The report on the 19th National Congress of the Communist Party of China pointed out that we must actively respond to the aging of the population, build a policy system and social environment for pension, filial piety and respect for the elderly, promote the integration of medical care, and accelerate the development of the cause and industry. China is one of the countries with a relatively high population aging population of the world. The elderly are large in scale and aging, and the task of aging population is the heaviest. Drawing on the experience of some developed countries in foreign countries to deal with the impact on aging through the establishment of long-term care insurance systems, the General Office of the Ministry of Human Resources and Social Security of China issued the "Guiding Opinions on Piloting the Long-Term Care Insurance System" (Human
Community Department [2016] No. 80) in July 2016, officially launched the pilot program of the social long-term care insurance system. The document pointed out that in the pilot phase of social long-term care insurance construction, the financing of social long-term care insurance funds needs to rely on its relationship of the basic medical insurance fund. Through the optimization of the basic medical insurance pooling account and personal accounts of urban employees, the transfer of fund balances, and the adjustment of insurance rates, the goal of financing the social long-term care insurance system will be achieved.

Whether it is from the increasing population aging trend in China or the increasing long-term care needs of our people, it is imperative to establish long-term social care insurance. The government departments have also actively responded to the voice in the society and officially started the exploration of building long-term social insurance. In such an environment, the issue of financing as a basic issue of social insurance 
operation is related to the sustainability of the operation of the system such as the cost-sharing mode and the level of system financing, and must be given sufficient attention. So that in the process of building social long-term care insurance against the future, it can combine the characteristics of social long-term care insurance and the actual situation of China's economy, politics and society to design a reasonable and efficient social long-term care insurance financing mechanism in line with China's national conditions, laying a solid foundation for the healthy and stable operation of social long-term care insurance.

\section{Literature Review}

\subsection{Foreign Literature}

In the foreign literature, the articles of country study on long - term insurance are also very common. Barr N (2010) studied in Japan, Sweden, Germany, the UK public long-term care system, for different countries adopted different long service suggests mode were analyzed, focusing on the distributional effects of different suggests mode as well as its financial burden, bring to the UK public long-term care system reform to provide reference [1]. Costa-Font J (2015), Courbage C (2015), Swartz K (2015) made a comparative analysis on the equity and effectiveness of the financing mode of public nursing system in the use of nursing resources in Germany, Japan and France, as well as the financial soundness of different modes [2]. Yang W (2016), Jingwei H A (2016), Fang L (2016) conducted an in-depth comparative study on the long term insurance system of three typical countries implementing social long term insurance in Germany, Japan and South Korea, and summarized relevant suggestions on financing mode selection and construction [3].

\subsection{Domestic Literature}

The research on the domestic practice of social long-term care insurance financing mechanism is mainly divided into two aspects: the introduction and analysis of the operation mode of social long-term care insurance in typical regions and the regional comparison. For example, Zhang Huifang (2016) and Lei peng (2016) introduced and analyzed the practice, experience and existing problems of the social insurance system construction in Qingdao, Nantong and Changchun [4-5]. Jiang Chongguang (2016) focused on the long-term insurance financing mechanism implemented in Taiwan, Qingdao, Nantong and other places in China [6]. Ling Muzi (2015) combined with the summary and analysis of existing practices at home and abroad, proposed that the contribution of long-term care insurance should be borne by the three parties (government, enterprises and individuals) [7]. Deng Dasong (2015) discussed the construction of China's long-term insurance system based on the analysis of the construction practice of long-term insurance in Qingdao [8]. Wang Fangqi (2016) made a comparative analysis of the public long care system in Shanghai, Qingdao and Nanjing, and concluded that it was more feasible to establish an independent insurance system for long-term care [9].

\section{The Social Long-term Care Insurance Financing Mechanism and Its Composition}

\subsection{Social Long-term Care Insurance Fund and Its Principle of Raising}

In theory, social long-term care insurance is a social and economic system, which is enforced by national legislation and establishes a nursing insurance fund through payment by employers and individuals to provide cash, material compensation or related care for the care and treatment of the insured person due to physical damage caused by the elderly, unable to take care of themselves, and long-term rehabilitation treatment and care. As the material basis and core content of the operation of the social long-term care insurance system, the social long-term care insurance fund is a special fund for the implementation of the nursing insurance system in accordance with the relevant laws, regulations and policies of the state. The social long-term care insurance fund is a compensatory fund provided by the state to protect workers and citizens from the risk of physical disability and enjoy socialized care services.

As the material basis and core content of the operation of the social long-term care insurance system, the social long-term care insurance fund economically guarantees the normal operation of the nursing insurance system. The main purpose of the Social Long-Term Care Insurance Fund is to provide financial support for the implementation of the social care insurance system. To ensure this is achieved without negatively affecting economic development, the raising of the social long-term care insurance fund should follow the following principles.

First, break even to ensure that the system is functioning properly. The balance of income and expenditure of the social long-term care insurance fund is the basic condition for the normal operation of the nursing insurance system. If the social long-term care insurance fund income is less than the expenditure, it will lead to the untimely or insufficient amount of social long-term care insurance fund payment, reduce the level of nursing insurance or affect the treatment and payment of the nursing insurance object, and thus affect its basic life. However, if the income of the nursing insurance fund exceeds the expenditure, which will lead to the overburden of the main tax and fee of the nursing insurance fund, which will affect the economic development. Especially in the important historical period of China's current economic restructuring and heavy burden of corporate taxes and fees, not increasing the burden of corporate contributions has become a basic condition for the financing of nursing insurance. In real life, the raising of nursing insurance funds generally takes the form of balance of payments and a slight balance.

Second, comprehensive balance will support the overall development of the economy and society. The raising of social 
long-term care insurance funds as a dynamic process should be carried out under certain constraints, including multiple steps and key points of fund raising, and ultimately require a financial balance. The realization of this goal requires that the social long-term care insurance fundraiser must scientifically design the entire operation process and key points to achieve the optimal goal under the constraints. Therefore, Liu Jintao and Chen Shuwen (2011) defined the social long-term care insurance financing mechanism as a set of scientific and reasonable institutional rules and institutional arrangements formulated by the social long-term care insurance managers in the social long-term care insurance fund raising activities, the purpose of which is to improve the quality of nursing insurance fund raising and promote the goal of raising funds [10].

\subsection{Elements of the Financing Mechanism for Long-term Care Insurance in Society}

A complete social long-term care insurance financing mechanism needs to address which subjects are responsible for financing, how the financing contribution responsibility is distributed among the various entities, how much is raised, and how to raise funds [voluntary/mandatory, fixed tax (fees) rate / Difference tax (fee) rate, tax/fee] and how to balance the income and expenditure of financing. Through the analysis of the existing articles on social long-term care insurance and the analysis of the social long-term care insurance financing mechanism, according to the social long-term care insurance financing process, this paper sorts out the following six social long-term care insurance financing mechanism elements, as shown in Figure 1.

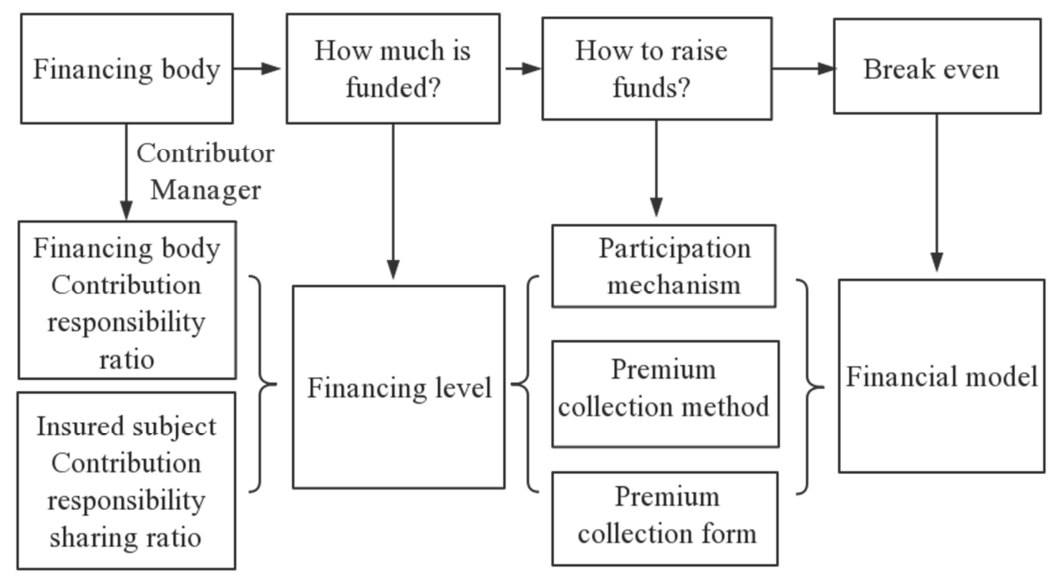

Figure 1. Element framework of financing mechanism.

\subsubsection{Financing Body}

The so-called "Financing body" refers to the objective object of participating in the overall process of social long-term care insurance financing and having specific responsibilities in it. It is the existence of these entities that ensures the effective financing of long-term care insurance funds and the smooth operation of the overall mechanism of social long-term care insurance financing. This paper defines the Financing body of the social long-term care insurance system as the main body responsible for the financing of social long-term care insurance, which includes not only individuals and organizations that are responsible for the contribution of the long-term care insurance system in accordance with the law, but also government agencies that are responsible for the formulation of the social long-term care insurance system, supervision and guidance of policy operation, and financial support according to laws and regulations. In countries where social long-term care insurance is implemented, the payment of social long-term care insurance taxes/fees is often the main source of social long-term care insurance funds. However, due to the large expenditure on social long-term care insurance, the wide coverage and the impact on the social economy are also large, for the sake of social mutual benefit and fairness, in order to ensure the financial adequacy and operational stability of social long-term care insurance, countries that implement social long-term care insurance often raise funds through other channels (such as government financial subsidies, state-owned assets, charity donation, medical insurance fund allocation, etc.) to supplement social long-term care insurance funds. And set up a special government agency, responsible for the formulation of the social long-term care insurance system, policy operation guidance and daily supervision.

There is also a difference in the proportion of different financing entities in the collection of social long-term care insurance funds. Generally speaking, in countries where social long-term care insurance is implemented, the main body of financing for insurance contributions is mainly corporate and individual contributions and government financial expenditures. In addition, countries that implement social long-term care insurance will also require the insured to pay a certain percentage of their expenses when receiving long-term care services, in order to curb excessive consumption and reduce the burden of insurance expenses.

\subsubsection{Insured Subject and Insurance Mechanism}

Insured subject refer to individuals and organizations that have the right to pay social long-term care insurance premiums/tax obligations in accordance with the law, and thereby enjoy the right to receive social long-term care insurance benefits in the event of long-term care expenditure 
needs.

The sharing ratio of the payment responsibility between different insured subjects is a problem that needs to be designed. Generally speaking, countries that implement social long-term care insurance systems are mostly insured by individuals or employers and employees. If the insured payment subject is only an individual within the insurance coverage, the payment responsibility is fully borne by the individual, and the government grants a subsidy to the group that has difficulty in payment. If the main subject of the insured payment involves both the employer and the employee, it is common practice for both parties to pay half of the premium, but some countries (such as Israel) will set different rates of contribution to employers and employees.

After determining the question of who is responsible for the financing responsibility of the social long-term care insurance system, it is necessary to solve how to truly incorporate the main body of the social long-term care insurance system into the system, so that they can participate actively and effectively in the financing of long-term care insurance in society, this is the insurance participation mechanism, which is generally divided into three categories: "mandatory insurance", "voluntary insurance" and "automatic registration".

\subsubsection{Financing Level}

Measuring social long-term care insurance financing level mainly through measuring social long-term care insurance protection items (such as whether to cover the expenses of professional medical institutions or nursing institutions, whether to cover home care or daily care, family reform and other expenditures), macro financing level (expenditure as a percentage of GDP), micro-finance level (expenditure as a percentage of total wages) and other indicators. Generally speaking, the level of financing for the social long-term care insurance system is affected by a variety of factors including the cost of social long-term care, the average income level of the insured population, the number of participants, the economic development level of a country, the degree of financial adequacy, the personal deductible of the person needing care, and the overall level of financing of the national social insurance.

The authors compiled data on the proportion of public long-term care expenditure in GDP in 26 OECD countries. As shown in Figure 2, it can be seen that the GDP share of public long-term care expenditure in OECD countries is relatively evenly distributed between $0.1 \%$ and $2 \%$.

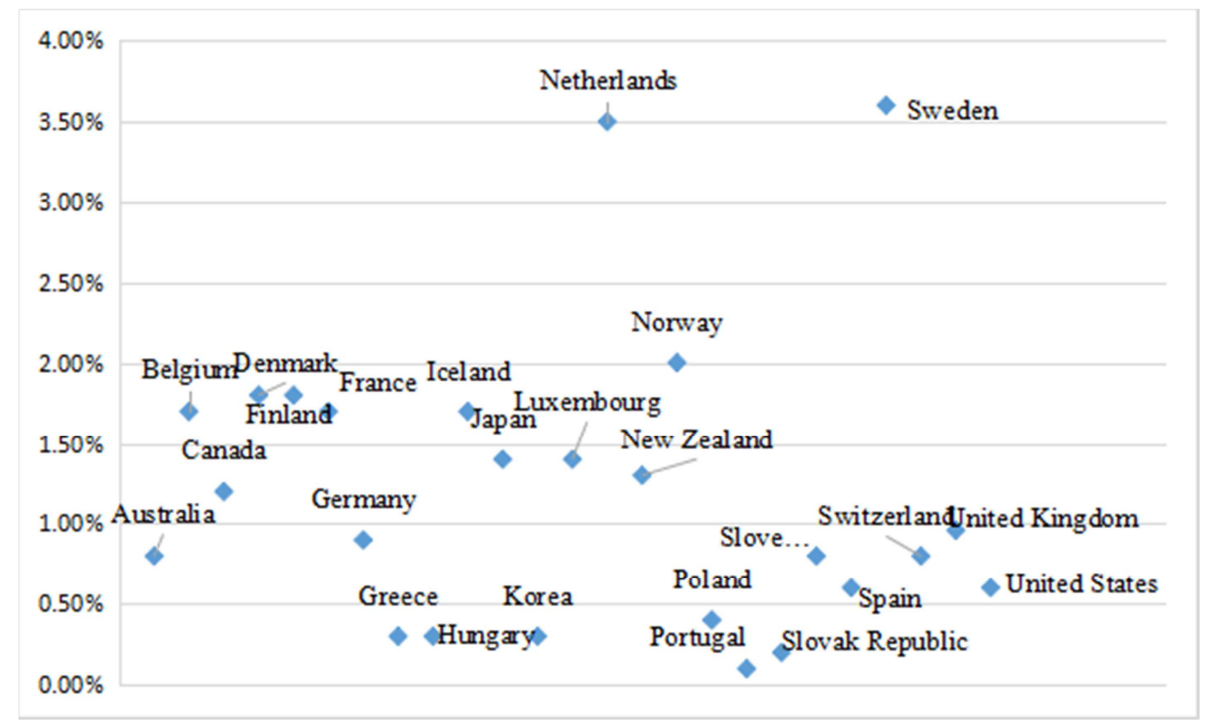

Source: Colombo f. Help Wanted? Providing and Paying for long-term Care [R]. OECD Publishing, 2011, 216-219.

Figure 2. GDP share of public long-term care in OECD countries.

At the same time, the nature of social long-term care insurance makes it naturally associated with social health insurance. Chen Chengcheng (2016), Lu Xuejing (2014) and Yan Xueli (2016) sorted out the insurance contribution rates of social medical insurance in Korea, Japan and Germany respectively, and by combing the insurance contribution rates for social medical insurance in Germany, Japan and Korea, we can see that the contribution rate of German social medical insurance is $14.6 \%$ (2015) of the insured's income, $8 \%$ in Japan, and $6.12 \%$ in Korea; Correspondingly, the total contribution rate of long-term care insurance in German society is $2.55 \%$ (2016) for insured persons, $1.55 \%$ (2013) for Japan, and $0.4 \%$ (2016) for Korea [11-13]. In Germany and
Japan, the contribution rate of social medical insurance is about 5 times that of social long-term care insurance, and the contribution rate of Korean social medical insurance is about 15 times that of long-term care insurance.

\subsubsection{Premium Collection Method}

Premium collection method for social long-term care insurance is the way to determine the amount of contributions for each participating entity. Premium collection method for social long-term care insurance can be generally divided into fixed tax/rate and differential tax/rate. Different premium collection methods have different characteristics and social economic effects, which have an important impact on social 
long-term care insurance expansion, fund raising, fairness and efficiency coordination.

Premium collection method for social long-term care insurance can also be classified according to the difference in the base of the premium calculation. In most countries, the calculation base is the pre-tax income of the insured, but some other countries choose to use basic medical insurance premiums as the basis for determining social long-term care insurance premiums, and use existing mature medical insurance premium collection systems to raise social long-term care insurance funds and improve the efficiency of fund collection and operation.

In addition to the above-mentioned method of premium collection, a way of raising premiums can be seen in practice, that is, each insured pays a fixed amount of premium according to the payment regulations, which is usually determined by considering the income, age, body and family status of the insured person, and will be adjusted with the long-term care expenses and fluctuations in prices.

\subsubsection{Premium Collection Form}

After determining the amount of premiums to be paid by the insured entities of the social long-term care insurance, it is necessary to solve the problem of which form/tool to collect the premiums payable by each insured subject as efficiently as possible. In order to avoid confusion with the concepts related to the existing literature, this paper defines the question of what form/tools to collect social long-term care insurance premiums as "the form of premium collection".

Generally speaking, the collection of social long-term care insurance premiums has two forms: social insurance tax and social insurance premium. Different forms of premium collection can achieve the purpose of collecting premiums for the insured. However, since these two forms of financing have their own characteristics, different forms of premium collection will in fact have different effects on the collection of premiums.

\subsubsection{Financial Model}

The "receipt" and "branch" of funds are two aspects of the opposition and unification of the operation and management of long-term care insurance funds in society. The raising of social long-term care insurance funds corresponds to the expenditure of social long-term care insurance funds, and there must be expenditures. On the one hand, the design of the financing mechanism should pay attention to the supply factors of the source of funds, on the other hand, it should also pay attention to the factors of capital expenditure, so as to determine the financing level more reasonably, ensure the balance of income and expenditure, and realize the efficient operation and management of funds.

There are two main financial models for financing modern social insurance systems: "pay as you go" and "accumulate". From these two modes, four financial models have gradually evolved: "pay as you go", "complete accumulation", "partial accumulation" and "nominal accounts".

\section{The Practice and Enlightenment of Long-term Care Insurance Financing at Home and Abroad}

\subsection{Practice of Long-term Care Insurance Financing in Typical Foreign Society}

Germany introduced a long-term care insurance system in 1995, which consists of two parallel compulsory insurance plans: social long-term care insurance for people with social health insurance, and commercial long-term care insurance for people who buy commercial health insurance. Social long-term care insurance pays cash by pay-as-you-go, while commercial long-term care insurance is funded in advance through collection of premiums. In 2004, Germany required retirees to pay for long-term care insurance, while in 2005, families with no children were required to pay higher long-term care insurance. In 2000, Japan established a public long-term care insurance system funded by premiums and taxes to cover approved actual service costs. The program covers the population aged 65 and over and the 40-64 age group with senile diseases. Insurance payments are provided in the form of services (physical) and cannot be paid in cash. The absence of cash payments is specifically designed to avoid the burden of care falling on (unpaid) female family members. South Korea established a long-term care insurance system within the framework of the National Health Insurance (NHl) system in 2008. The government requires $20 \%$ of institutional care and $15 \%$ of home care users, including support for daily living, as well as transportation, day/night care, short-term intensive care and equipment, including wheelchairs and orthopedic mattresses. The central government is responsible for overall guidance and supervision, and the local government is responsible for the establishment, review and supervision of the nursing institutions, and the health insurance institutions supervised by the Ministry of Health and Welfare are responsible for the specific operations. The specific content of the financing mechanism of the three countries is shown in Table 1.

From the actual operation effect of the long-term care insurance system in various countries, Germany's public insurance covers about 70 million people, and the remaining 9 million higher-income people choose to buy private insurance instead of participating in the government's plan. About 2 million Germans (2.4\% of their population) are currently enjoying long-term care insurance benefits. Two-thirds of people have chosen home care. Since the establishment of the program, there has been a small increase in the demand for nursing equipment, and the cost of institutional care has increased from $42 \%$ to $48 \%$. According to the statistics of the German Federal Ministry of Health, from 1995 to 1998, the insurance premiums for social nursing insurance totaled 5.5 billion euros, and the insurance premiums began to exceed the insurance premiums after 1999. The annual deficit of the annual care insurance premium in 2004 reached 820 million euros. 
Table 1. List of social long-term care insurance financing mechanism in Germany, Japan and South Korea.

\begin{tabular}{|c|c|c|c|}
\hline & Germany & Japan & Korea \\
\hline \multirow[t]{3}{*}{ Financing body } & $\begin{array}{l}\text { individuals and businesses (about } 66 \% \text { ) }+ \\
\text { government (about } 34 \% \text { ) }\end{array}$ & $\begin{array}{l}\text { government taxation }(50 \%)+\text { people over } 40 \\
\text { years old and their employers }(50 \%)\end{array}$ & $\begin{array}{l}\text { Personal and corporate } \\
\text { contributions }(60 \%-65 \%)+ \\
\text { Government }(20 \%)+\text { Personal } \\
\text { self-pay (Nursing home: } 20 \% \text {, } \\
\text { home care: } 15 \%)\end{array}$ \\
\hline & $\begin{array}{l}\text { Personal self-pay: home care }(25 \%) \text {, } \\
\text { institutional mutual benefit }(50 \%)\end{array}$ & $\begin{array}{l}\text { Personal self-pay: } 20 \% \text { of income exceeds the } \\
\text { requirement }\end{array}$ & \\
\hline & Central financial setting adjustment fund & $\begin{array}{l}\text { The first type of insured person over the age of } \\
65(22 \%)\end{array}$ & \\
\hline \multirow{3}{*}{ Insured subject } & $\begin{array}{l}\text { Individuals }(50 \%) \text {, enterprises }(50 \%) \text {, } \\
\text { retirees and their pension funds each bear } \\
50 \%\end{array}$ & $\begin{array}{l}\text { The second type of insured person aged } 40-46 \\
(28 \%)\end{array}$ & $\begin{array}{l}\text { enterprises }(50 \%) \text {, individual } \\
(50 \%)\end{array}$ \\
\hline & $\begin{array}{l}\text { Follow the medical insurance, medical } \\
\text { insurance participants directly included in } \\
\text { the scope of long-term insurance coverage }\end{array}$ & $\begin{array}{l}\text { Incumbent staff premium: corporate and } \\
\text { individual guarantees } 50 \%\end{array}$ & \\
\hline & $\begin{array}{l}\text { Poverty and vulnerable groups can } \\
\text { receive subsidies or relief }\end{array}$ & $\begin{array}{l}\text { Self-employed person premium: } 50 \% \text { of personal } \\
\text { burden (the other half is financially burdened) } \\
\text { Poverty and vulnerable groups can receive } \\
\text { subsidies or relief }\end{array}$ & (follow medical insurance) \\
\hline \multirow{2}{*}{$\begin{array}{l}\text { Institutional GDP } \\
\text { Participation } \\
\text { mechanism }\end{array}$} & $0.90 \%(2011)$ & $1.40 \%(2011)$ & $0.30 \%(2011)$ \\
\hline & Mandatory universal enrollment & Mandatory insurance & Mandatory universal enrollment \\
\hline \multirow{3}{*}{$\begin{array}{l}\text { Premium } \\
\text { collection method }\end{array}$} & Differential rate & $\begin{array}{l}\text { The first type of insured person: multiplied by a } \\
\text { certain amount based on the income of the } \\
\text { insured Five-rate rate determination for high and } \\
\text { low settings, and the higher the income, the } \\
\text { higher the rate. }\end{array}$ & $\begin{array}{l}6.55 \% \text { of health insurance } \\
\text { premiums, about } 0.4 \% \text { of wages, } \\
\text { half paid by employees and } \\
\text { employers ( } 2016)\end{array}$ \\
\hline & $\begin{array}{l}2.55 \% \text { of employees' pre-tax income, half } \\
\text { of employers and employees (2017) }\end{array}$ & $\begin{array}{l}\text { The second type of insured: } 1.55 \% \text { of monthly } \\
\text { income (Japan Association Health Insurance, } \\
\text { 2013) }\end{array}$ & \\
\hline & $\begin{array}{l}\text { Children over the age of } 23 \text { who have no } \\
\text { children will be required to pay an } \\
\text { additional premium of } 0.25 \% \text { (since 2005) } \\
\text { Rate dynamic adjustment }\end{array}$ & Rate dynamic adjustment & \\
\hline $\begin{array}{l}\text { Premium } \\
\text { collection form }\end{array}$ & Social Security fee & $\begin{array}{l}\text { Social Security fee } \\
\text { The first type of insured premiums are deducted } \\
\text { directly from the annuity by the local government } \\
\text { or transferred by themselves. } \\
\text { The second type of insured premium is collected } \\
\text { along with the medical insurance premium. } \\
\text { Social Security fee } \\
\text { Pay-as-you-go }\end{array}$ & \\
\hline
\end{tabular}

Note: the author sorted out according to the literature.

Since 2005, Germany's contribution rate for childless insured persons has increased by $0.25 \%$, and the fund deficit has since decreased. After raising the contribution rate by $0.25 \%$ in 2008 , the fund began to earn a surplus. As of the end of 2014, the social long-term care insurance surplus was 460 million euros. At the same time, compulsory social insurance premiums do not cover the full cost of long-term care. It is estimated that German mandatory long-term care insurance can only pay about $43 \%$ of the total cost of nursing homes and about $47 \%$ of those who are heavily dependent. In absolute terms, the average annual coverage gap for people with low and high dependency levels in Germany is $\$ 20,700$ and $\$ 26,700$ per person, respectively. In addition to supplementing long-term insurance payments, Germany has successfully incorporated long-term care into the system of social insurance systems. This system is currently financially sound.

According to the latest information from the Ministry of
Health, Labor and Welfare of Japan, the total cost of care in Japan in 2000 was 3.6 trillion yen. In 2005, it has increased to 6.4 trillion yen. In 2015, it increased to 10.1 trillion yen, and in 1991, it increased by 1.81 times. In addition, the number of nursing premiums paid by individuals in Japan is also increasing. The national average for Class 1 insurance premiums in 2000-2002 is 2,911 yen per month, and in $2003-2005$ it is increased by $13 \%$ to 3,293 yen. In 2008 , the national average premium increased by $24 \%$ to 4,090 yen, and the national average premium for 2009-2011 reached 4,160 yen. In 2012-2014, the increase was $20 \%$, and the per capita insurance premium for the elderly reached 4,972 yen. It is expected that this value will reach 5,514 yen in 2015-2017. Increasing costs are an important issue for Japan's long-term care system.

In summary, social insurance emphasizes government responsibility. The state needs to invest a large amount of funds 
to ensure the operation of the social long-term care insurance system, for example, Japan needs to invest $50 \%$ of the funds in long-term care premiums. Under the trend of prolonged population structure and long-term care, the funds raised from the original insurance rates are difficult to adapt to the substantial increase in the cost of care, resulting in the government investing a large amount of funds to supplement, putting a heavy financial burden on the country. However, because the benefits of long-term care insurance need to be assessed and identified, and the assessment tools, assessment processes, and certification standards vary from country to country, there is no close relationship between the number of long-term care insurance beneficiaries and the funding mechanism.

\subsection{Domestic Practice}

According to Lei Peng and $\mathrm{Wu}$ Yaochun (2016) on the long-term insurance system of Qingdao and Nantong, we know that Qingdao's long-term care insurance system was established in 2012, and the original intention was to meet the challenges of aging, to protect the disabled, and to meet the medical care needs of the semi-disabled crowd. The protection of long-term care insurance in Nantong City is the employee medical insurance and the resident medical insurance insured in the urban area. The system adopts the diversified design of the fund-raising body, but does not rely on the basic medical insurance. In addition to financing through the allocation of the Basic Medical Insurance Fund, the insured individual contribution standard has been set up, opening up a relatively independent source of funding for the long-term care insurance system [14]. The long-term care insurance system of Changchun City is mainly for the disabled group, and the long-term care insurance fund is mainly used to compensate the daily care and professional medical care expenses of the completely disabled. The list of social long-term care insurance financing mechanisms in Qingdao, Nantong and Changchun is shown in Table 2.

Table 2. List of social long-term care insurance financing mechanisms in Qingdao, Nantong and Changchun.

\begin{tabular}{|c|c|c|c|}
\hline & Qingdao & Nantong & Changchun \\
\hline \multirow{4}{*}{ Financing body } & $\begin{array}{l}\text { Medical insurance fund } \\
\text { allocation: more than } 20 \% \text { of the } \\
\text { basic medical insurance over the } \\
\text { years of the balance fund; }\end{array}$ & $\begin{array}{l}\text { Personal payment-- } \\
\text { Employees: Medical insurance agencies are uniformly } \\
\text { transferred from medical insurance personal medical } \\
\text { accounts; Residents: pay the residents' basic medical } \\
\text { insurance premiums when they are paid; }\end{array}$ & $\begin{array}{l}\text { Medical insurance fund allocation: } \\
10 \% \text { of the annual balance of the basic } \\
\text { medical insurance pooling fund; }\end{array}$ \\
\hline & $\begin{array}{l}\text { Employees: Monthly transfer } \\
\text { from the employee basic medical } \\
\text { insurance fund according to the } \\
\text { monthly average of } 0.50 \% \text { of the } \\
\text { individual account; }\end{array}$ & $\begin{array}{l}\text { Medical insurance pooling fund raising-- } \\
\text { At the beginning of each year, according to the } \\
\text { employee medical insurance and the number of } \\
\text { residents' medical insurance who participated in the } \\
\text { long-term care insurance, they were raised from the } \\
\text { employee medical insurance pooling fund and the } \\
\text { resident medical insurance pooling fund respectively; }\end{array}$ & $\begin{array}{l}\text { Employees: transferred from the } \\
\text { pooled fund and } 0.2 \text { percentage points } \\
\text { from the individual account according } \\
\text { to the } 0.3 \text { percentage points of the } \\
\text { personal account included in the } \\
\text { medical insurance; }\end{array}$ \\
\hline & $\begin{array}{l}\text { Residents: no more than } 10 \% \text { of } \\
\text { the total amount of social medical } \\
\text { insurance premiums paid by } \\
\text { residents in that year, transferred } \\
\text { from the residents' social medical } \\
\text { insurance fund }\end{array}$ & Government -- & $\begin{array}{l}\text { Residents: Extracted from the resident } \\
\text { medical insurance fund at a rate of } 30 \\
\text { yuan per person per year; }\end{array}$ \\
\hline & Government: Financial subsidies & $\begin{array}{l}\text { The municipal finance is allocated at one time at the } \\
\text { beginning of each year; Investment in business, charity, } \\
\text { etc. }\end{array}$ & Government: Financial subsidies \\
\hline $\begin{array}{l}\text { Participation } \\
\text { mechanism }\end{array}$ & Follow medical insurance & Follow medical insurance & Follow medical insurance \\
\hline $\begin{array}{l}\text { Premium } \\
\text { collection } \\
\text { method }\end{array}$ & $\begin{array}{l}\text { Follow medical insurance, } \\
\text { Enterprises and individuals do not } \\
\text { need to pay separately }\end{array}$ & $\begin{array}{l}\text { Follow medical insurance, a fixed amount; } 100 \text { yuan } \\
\text { per person per year, personal payment ( } 30 \text { yuan), } \\
\text { medical insurance pooling fund based on the number of } \\
\text { people transferred ( } 30 \text { yuan) and government subsidies } \\
\text { ( } 40 \text { yuan) (2016) }\end{array}$ & $\begin{array}{l}\text { Follow medical insurance, Enterprises } \\
\text { and individuals do not need to pay } \\
\text { separately }\end{array}$ \\
\hline $\begin{array}{l}\text { Premium } \\
\text { collection form }\end{array}$ & $\begin{array}{l}\text { Follow medical insurance, } \\
\text { Enterprises and individuals do not } \\
\text { need to pay separately }\end{array}$ & Follow medical insurance, social insurance premiums & $\begin{array}{l}\text { Follow medical insurance, Enterprises } \\
\text { and individuals do not need to pay } \\
\text { separately }\end{array}$ \\
\hline Financial model & Pay-as-you-go & Pay-as-you-go & Pay-as-you-go \\
\hline
\end{tabular}

Note: The author sorted out according to the literature.

By comparison, we can see that except for Nantong, there are no individual contributions and financial inputs in other pilot areas, and they all rely on the medical insurance fund for financing. Changchun and Qingdao are very similar: First, a certain percentage of basic medical insurance fund balance funds are transferred as a start-up fund at one time. Among them, Changchun is $10 \%$ of the balance of urban basic medical insurance pooling funds, and Qingdao is $20 \%$ of the balance of employee medical insurance over the years; The second is to raise funds by adjusting the overall fund and personal account structure, and the unit, individual, and finance do not pay fees. Among them, Changchun adopts the method of transferring individual accounts $(0.20 \%)$ and unified funds $(0.3 \%)$, and the employee medical insurance 
insured persons and urban residents' medical insurance insured persons without personal accounts are all allocated by the unified fund; Qingdao employee medical insurance is cut from the share of the unified fund originally allocated to the personal account by $0.5 \%$, and the resident medical insurance is the unified fund transfer. Shanghai has mixed long-term care insurance funds into the medical insurance pooling fund, and has not built a fund pool.

Nantong is an area that truly establishes the payment of fees by individuals, governments and medical insurance funds. Nantong implements a system of integration of all people, and raises an average of 100 yuan per person per year. Among them, the individual pays 30 yuan, the urban workers are deducted from the personal account, the individual residents pay, and the civil administration personnel (rescue groups), minors, students and children are fully subsidized by the financial department; The medical insurance fund is transferred at a rate of 30 yuan per person per year; the government subsidizes 40 yuan per person per year.

It can be seen that there are major differences in the pilot programs in various pilot areas in China. In the long run, it will affect the final formation of the system and bring about serious fragmentation.

\section{Policy Recommendations}

Combining the practical experience of Germany, Japan and South Korea and China's Qingdao, Nantong and Changchun, the author suggests that China's long-term care insurance financing mechanism should pay attention to the following issues.

\subsection{Financing Body: Multiple Financing Subject}

In the choice of Financing body setting, international experience generally adopts the mode of multiple financing subject, which is shared by employers and employees (Germany), and is also independently paid by employees. At present, the total payment rate of corporate social insurance in China is too high and the burden is too heavy, while the personal medical insurance contributions of the employees almost do not fulfill the payment obligation, and the individual contributions are fully allocated to individual accounts. As of the end of 2016, the balance of China's medical insurance personal accounts was 520 billion yuan. In the context of the current implementation of structural adjustments and lower corporate rates as an important political goal, we can take this opportunity to balance the share of units and individuals in medical insurance and long-term care insurance contributions. Under the condition of not increasing the additional payment burden of the enterprise, the long-term care insurance fund shall be raised by transferring a certain proportion of the payment of the medical insurance enterprise or by transferring a certain proportion of the balance of the medical insurance pooling account fund.

Regarding the payment method of individual contributions, whether it is paid by individuals or by individual accounts, we believe that in order to ensure the orderly advancement of the system, it is not appropriate for individuals to pay additional fees, but should be allocated from their personal accounts. For those who do not have a personal account, the people who participate in the medical insurance policy construction system should be paid by the individual, because the premium amount of the single construction system is far lower than the unified account combination mode, and should be paid by the individual. As the level of aging further deepens, it may be considered to ease the pressure on the fund's revenue and expenditure by gradually increasing the personal payment responsibility and appropriately increasing the proportion of individual contributions. For groups that do have difficulties, some subsidies can be given by the government.

In addition, on the issue of the sharing of contributions, combined with the existing international practices and China's policy orientation, this paper suggests that individuals who receive social long-term care insurance benefits are required to set a $15 \%$ (home care) or $20 \%$ (institutional care) payout ratio when receiving long-term care services, the financing for the remaining part of the expenditure is $50 \%$ for individual and corporate contributions respectively, and $30 \%$ to $35 \%$ for government finance and other contributions. At the same time, with reference to the German and Japanese practices, the central government has specifically allocated a certain percentage of funds as a transfer fund in the financing ratio it is responsible for, so as to stabilize the excessive gap in the payment of long-term care insurance fees in different regions.

\subsection{Insured Subject and Insurance Participation Mechanism: Follow Medical Insurance and Automatically Register for Insurance}

Drawing on the existing practical experience at home and abroad, this paper suggests that the insured entity of social long-term care insurance should follow the method of medical insurance, directly participate in the social long-term care insurance system for those who participate in basic medical insurance, strengthen personal responsibility in the distribution of the premium burden of the insured subject and formulate special long-term care insurance premium collection policies for retirees, no longer increase the burden on enterprises, so as to reduce the system's resistance and improve the system's feasibility.

The implementation of compulsory insurance for urban workers is to avoid possible adverse selection problems, rapidly expand the system coverage, and improve the quality of insurance risk pools, so that the insurance system can better play the role of risk dispersion and accelerate the rapid accumulation of insurance funds. However, due to the existing urban-rural differences in China, the basic medical insurance actually implements the mechanism of mandatory participation of urban workers and voluntary participation of urban and rural residents. In the case of following the medical insurance to determine the insured subject of social long-term care insurance, considering the possibility of low participation rate of urban and rural residents' voluntary 
participation, this paper proposes to adopt the automatic registration insurance mechanism for urban and rural residents. All urban and rural residents who participate in basic medical insurance are automatically included in the social long-term care insurance system, and at the same time give them the option to withdraw.

\subsection{Premium Collection Method: Follow the Medical Insurance and Implement Differential Rates}

With the continuous adjustment of China's population structure, the level of long-term care needs, the level of expenditure, and the constant changes in the size and income level of the insured, China should learn from the practices and experiences of Germany, Japan and South Korea. Set up a normal adjustment mechanism for social long-term care insurance rates (premium) to monitor the long-term care insurance operation and income and expenditure of the society, and adjust the social long-term care insurance premium rate (premium) accordingly. At the same time, it is also necessary to refer to international experience to levy long-term care insurance premiums for retirees receiving annuity with a limit on their personal accounts, in order to prevent institutional financial difficulties caused by the decline in the number of socially aging people and the rapid increase in the benefits of treatment. Finally, for the sake of fairness and actuarial considerations, it is recommended to set different insurance rates (premium) for the population who choose not to have children and those who choose to have children to ensure the financial balance and financial stability of the system and improve the solvency of the system.

\subsection{Premium Collection Form: Social Insurance Premium, Co-financing with Medical Insurance}

Under the premise that the insured subject of the social long-term care insurance, the insurance participation mechanism and the insurance fund-raising method have followed the basic medical insurance, the use of the existing mature basic medical insurance premium collection system to raise the social long-term care insurance funds will become the best premium collection form. However, with the rapid increase in the level of medical consumption and the general increase in the level of medical insurance benefits, the safety risks of medical insurance funds have further increased. According to the statistics of Wu Ritu (2015), In 2013, the pooling funds for urban workers' medical insurance in 225 regions across the country were unable to offset their current income, and the accumulated balance of the pooling funds in 22 regions was in deficit [15]. In the case that the level of medical insurance contributions cannot be increased, there will be more and more co-ordination of regional medical insurance fund balances facing difficulties. Therefore, the use of medical insurance pool balances to transfer long-term care insurance is bound to be unsustainable.

In order to reduce the burden of payment for the insured subject, the author believes that the premiums determined according to the differential rate or different payment grades above can be converted to a separate long-term care insurance contribution by optimizing the current account structure and rates of health insurance, and by a certain percentage (such as $1 \%$ ) of medical insurance contributions. The existing agencies responsible for collecting basic medical insurance premiums are levied together with basic medical insurance premiums, divided and accounted for, and managed separately to achieve independent raising of long-term care insurance premiums. When the existing transfer rate cannot meet the long-term care insurance expenditure demand, the long-term care insurance rate can be adjusted by means of actuarial means to ensure the financial balance of the social long-term care insurance system.

\subsection{Financing Level: The Total Financing Level of Social Long-term Care Insurance Accounts for 1\% of GDP}

As mentioned earlier, the proportion of public long-term care expenditure in OECD countries (the proportion of GDP is relatively evenly distributed between $0.1 \%$ and $2 \%$ ). Therefore, by selecting $0.5 \%, 1 \%, 1.5 \%, 2 \%$ and other representative public long-term care expenditure levels, combined with the contribution ratio of each Financing body proposed in the previous article, based on China's real GDP level, urban workers and the average income level of urban and rural residents and the number of people participating in medical insurance, this paper estimates total payment rate of social long-term care insurance corresponding to different financing levels; At the same time, with reference to the relationship between social long-term care insurance and social medical insurance in Germany, Japan and South Korea, the social medical insurance is the assumption of 5 times and 15 times of the long-term care insurance contribution rate, and in the case that the current medical insurance company's contribution rate is $6 \%$, the corresponding total social long-term care insurance contribution rate is estimated. After calculation and analysis, the paper draws the results of the total social insurance premium rate of $1.2 \%$ and $0.4 \%$.

Taking into account the relationship between the several major types of social insurance, as well as the pressure and operating costs of the national insurance, individuals, and enterprises for the total premiums of various types of insurance, this paper believes that the level of financing for long-term care insurance should also be controlled within $1 \%$ to avoid excessive burdens on the healthy development of the country's social economy.

\subsection{Financial Model: Partial Accumulation System}

With reference to the experience of financial model selection of foreign social long-term care insurance financing mechanism, considering the impact of the future population aging peak on the financial sustainability of social long-term care insurance system, this paper believes that China's social long-term care insurance financing mechanism should still choose partial accumulation system. In the specific operation, actuarial means can be used to determine a slightly higher total 
rate than the current pay-as-you-go system. In addition to the current payment for the current long-term care costs, the funds raised can also be reserved for accumulation in order to cope with the impact of the long-term care costs in the future when the peak of China's population ages.

In summary, this paper believes that in the future construction of social long-term care insurance, China should focus on the design of a reasonable social long-term care insurance financing mechanism from the five elements of the social long-term care insurance financing mechanism. In determining the social long-term care insurance financing mechanism, it should adopt a variety of financing entities, including the main body of contributions, financial support, medical insurance fund allocation, state-owned assets realization, charitable donations, etc. Among them, the insured subject pays about $50 \%$ of the social long-term care expenditure, the financial and other contributing party pays $30 \%-35 \%$, and the individual pays $15 \%-20 \%$; Insured subjects that are consistent with the main body of the basic medical insurance, strengthen personal responsibility and do not increase the burden on the enterprise. In the short term, employees and urban and rural residents should establish different financing systems, namely, the establishment of mandatory participation policies for urban workers and the automatic registration of urban and rural residents. Urban workers pay at the prescribed rate, and differentiate between the fertility group and the voluntary non-fertility group, and calculate and pay the premium based on the pre-tax salary. The urban and rural residents choose the different premiums for the insurance premiums, and set the premium collection method for the normalized premium adjustment mechanism. In the form of payment, transfer some medical insurance contributions into independent long-term care insurance premiums, and adopt the form of premium collection with the basic medical insurance, sub-accounting, and independent management. Financing is carried out at a system financing level of no more than 1\% of GDP; and by adopting a partially accumulated financial model, the financial sustainability of long-term care insurance brought about by the accelerated population aging is guaranteed. Only by establishing a diversified payment entity and a fund-raising responsibility sharing mechanism can we ensure the healthy and sustainable development of China's long-term care insurance business.

\section{Acknowledgements}

This paper is the phased achievement of the key project of Beijing social science, "a study on the social support for the incapacitated and semi-incapacitated elderly in the capital" (project no. 19GLA008).

\section{References}

[1] Barr N. "Long-Term Care: A Suitable Case for Social Insurance". Social Policy \& Administration, 2010, 44 (4): 359-374.

[2] Costa-Font J, Courbage C, Swartz K. "Financing long-term care: ex ante, ex post or both?" Health Economics, 2015, 24 (Supplement): 45-57.

[3] Yang W, Jingwei H A, Fang L, et al. "Financing institutional long-term care for the elderly in China: a policy evaluation of new models". Health Policy and Planning, 2016, 31 (10): 1391.

[4] Zhang Huifang, Lei Xiansheng. Research on local practice, experience summary and problems of exploring long-term care insurance in China [J]. Contemporary economic management, 2016, (09): 91-97.

[5] Lei Peng, Wu Zhuchun. Current situation and thinking on the construction of long-term care system in China -- based on practice exploration in Qingdao, nantong and changchun [J]. China medical insurance, 2016, (02): 23-26.

[6] Jiang Chongguang. Study on financing model of long-term care plan in Taiwan and its reference significance [D]. Graduate school of Chinese academy of social sciences, 2016.

[7] Ling Muzi. Research on financing mechanism of China's elderly long-term care insurance [D]. Dongbei university of finance and economics, 2016.

[8] Deng Dasong, Guo Ting. Analysis on the construction of China's long-term care insurance system -- a case study of Qingdao [J]. Health economics research, 2015, (10): 33-37.

[9] Wang Fangqi. Long-term care insurance system: breaking the ice in Beijing [N]. China insurance news, 2015-05-21 (002).

[10] Liu Jintao, Chen Shuwen, 2011. Research on the financing mechanism of long-term care insurance for the aged in China. Journal of dalian university of technology (social science edition), (3): 44-48.

[11] Chen Chengcheng, 2016. Overview of long-term care insurance in Korea. Civil administration of China (17): 38-41.

[12] Lv Xuejing, 2014. Financing and cost control measures of Japanese medical insurance. China medical insurance (5): 68-70.

[13] Sui Xueli, 2016. Analysis on the reform path of German medical insurance financing system - based on the perspective of population aging and family policy. Journal of beihang university (social science edition) (2): 13-19.

[14] Lei Peng, Wu Zhuochun, 2016. Current situation and thinking of long-term care system construction in China -- based on practical exploration in Qingdao, nantong and changchun. China medical insurance (2): 23-26.

[15] Wu Ritu, 2015. Deepening the reform of social security system to adapt to the new normal of economic development. National People's Congress of China (3): 36-39. 